\title{
A Single Nucleotide Substitution of GSAM Gene Causes Massive Accumulation of Glutamate 1-Semialdehyde and Yellow Leaf Phenotype in Rice
}

Qian Wang ${ }^{1,2+}$, Baiyang Zhu ${ }^{2+}$, Congping Chen², Zhaodi Yuan², Jia Guo², Xiaorong Yang ${ }^{2}$, San Wang², Yan Lv², Qingsong Liü ${ }^{2}$, Bin Yang ${ }^{2}$, Changhui Sun ${ }^{1,2}$, Pingrong Wang ${ }^{1,2^{*}}$ and Xiaojian Deng ${ }^{1,2^{*}}$ (D)

\begin{abstract}
Background: Tetrapyrroles play indispensable roles in various biological processes. In higher plants, glutamate 1semialdehyde 2,1-aminomutase (GSAM) converts glutamate 1-semialdehyde (GSA) to 5-aminolevulinic acid (ALA), which is the rate-limiting step of tetrapyrrole biosynthesis. Up to now, GSAM genes have been successively identified from many species. Besides, it was found that GSAM could form a dimeric protein with itself by x-ray crystallography. However, no mutant of GSAM has been identified in monocotyledonous plants, and no experiment on interaction of GSAM protein with itself has been reported so far.

Result: We isolated a yellow leaf mutant, ys53, in rice (Oryza sativa). The mutant showed decreased photosynthetic pigment contents, suppressed chloroplast development, and reduced photosynthetic capacity. In consequence, its major agronomic traits were significantly affected. Map-based cloning revealed that the candidate gene was LOC_ Os08g41990 encoding GSAM protein. In ys53 mutant, a single nucleotide substitution in this gene caused an amino acid change in the encoded protein, so its ALA-synthesis ability was significantly reduced and GSA was massively accumulated. Complementation assays suggested the mutant phenotype of ys 53 could be rescued by introducing wild-type OsGSAM gene, confirming that the point mutation in OSGSAM is the cause of the mutant phenotype. OsGSAM is mainly expressed in green tissues, and its encoded protein is localized to chloroplast. qRT-PCR analysis indicated that the mutation of OsGSAM not only affected the expressions of tetrapyrrole biosynthetic genes, but also influenced those of photosynthetic genes in rice. In addition, the yeast two-hybrid experiment showed that OsGSAM protein could interact with itself, which could largely depend on the two specific regions containing the 81th-160th and the 321th-400th amino acid residues at its N- and C-terminals, respectively.
\end{abstract}

Conclusions: We successfully characterized rice GSAM gene by a yellow leaf mutant and map-based cloning approach. Meanwhile, we verified that OsGSAM protein could interact with itself mainly by means of the two specific regions of amino acid residues at its $\mathrm{N}$ - and C-terminals, respectively.

Keywords: Rice, Tetrapyrrol biosynthesis, GSAM gene, Protein interaction, Chloroplast development, Yellow leaf mutant, Gene cloning

\footnotetext{
* Correspondence: prwang@sicau.edu.cn; xjdeng@sicau.edu.cn

${ }^{\dagger}$ Qian Wang and Baiyang Zhu contributed equally to this work.

'State Key Laboratory of Crop Gene Exploration and Utilization in Southwest

China, Sichuan Agricultural University, Chengdu 611130, China

Full list of author information is available at the end of the article
}

\section{Springer Open}

(c) The Author(s). 2021 Open Access This article is licensed under a Creative Commons Attribution 4.0 International License, which permits use, sharing, adaptation, distribution and reproduction in any medium or format, as long as you give appropriate credit to the original author(s) and the source, provide a link to the Creative Commons licence, and indicate if changes were made. The images or other third party material in this article are included in the article's Creative Commons licence, unless indicated otherwise in a credit line to the material. If material is not included in the article's Creative Commons licence and your intended use is not permitted by statutory regulation or exceeds the permitted use, you will need to obtain permission directly from the copyright holder. To view a copy of this licence, visit http://creativecommons.org/licenses/by/4.0/. 


\section{Background}

Tetrapyrroles play vital roles in various key biological processes, including photosynthesis and respiration (Ilag et al. 1994; Mochizuki et al. 2010). There are four classes of tetrapyrroles in higher plants, namely, chlorophyll (Chl), heme, siroheme, and phytochromobilin (Tanaka et al. 2011). All of these tetrapyrroles are derived from a common biosynthetic pathway that resides in the plastid, in which eight molecules of 5-aminolevulinic acid $(\delta$ aminolevulinic acid, ALA) are assembled into the tetrapyrrole core structure (Ge et al. 2010).

The synthesis of ALA in animals, fungi and some bacteria was a condensation of glycine and succinylcoenzyme A by ALA synthase (Tanaka and Tanaka 2007). However, in plants, algae and some photosynthetic bacteria, ALA is usually derived from the glutamate, which is called the five-carbon pathway (Grimm et al. 1991). In higher plants, ALA is the universal precursor of all tetrapyrroles, and its synthesis process is the rate-limiting step of tetrapyrroles biosynthesis (Lytovchenko et al. 2011). ALA was formed by transferance of the amino group of glutamate 1-semialdehyde (GSA) from C2 to $\mathrm{C} 1$, which was catalyzed by glutamate 1-semialdehyde 2,1-aminomutase (GSA aminotransferase, GSAM) (Grimm et al. 1991).

GSAM belongs to class-III pyridoxal-phosphatedependent aminotransferase family (https://www. uniprot.org/uniprot/Q6YZE2), which was widely found in photosynthetic algae and plants (Song et al. 2016). In higher plants, the GSAM protein was first purified from the de-etiolated barley (Hordeum vulgare) seedings (Grimm et al. 1989), and GSAM genes have been successively identified from many species, such as soybean (Glycine max, Sangwan and O'Brian 1993), Arabidopsis (Song et al. 2016), tobacco (Nicotiana tabacum, Höfgen et al. 1994; PöRs et al. 2001), tomato (Lycopersicon esculentum, Polking et al. 1995; Lytovchenko et al. 2011), and Brassica napus (Tsang et al. 2003a). However, no mutant of GSAM has been identified in monocotyledonous plants. On the other hand, it was found that the GSAM could form a dimeric protein with itself (Grimm et al. 1989; Stetefeld et al. 2006; Ge et al. 2010), and different subunit states could show negative synergy when working (Hennig et al. 1997). Nonetheless, almost all researches on the dimeric structures of GSAM were conducted by $\mathrm{x}$-ray crystallography, and no experiment on interaction of GSAM protein with itself has been reported so far.

In our research, we isolated a yellow leaf mutant, ys53, in rice (Oryza sativa). The mutant showed yellow phenotype throughout the whole growth period. Its photosynthetic pigment contents were decreased, and the chloroplasts showed obvious developmental impairment. In consequence, its major agronomic traits were significantly affected. Map-based cloning, intermediate product detection and complementation assays suggested that a single nucleotide mutation in OsGSAM (LOC_Os08g41990) is the reason for the mutant phenotype. OsGSAM is mainly expressed in green tissues and its encoded protein is localized to chloroplast. In addition, the yeast two-hybrid experiment showed that OsGSAM protein could interact with itself mainly by means of the two specific regions of amino acid residues at its $\mathrm{N}$ - and C-terminals, respectively.

\section{Results}

Isolation and Characterization of the ys53 Mutant

The ys53 mutant was obtained from japonica rice variety Nipponbare by ethyl methanesulfonate (EMS) mutagenesis. It exhibited a yellow leaf phenotype throughout the whole growth period, and grew at a slow rate (Fig. 1a, b), which caused its heading period to be delayed by 7 days (Fig. 1c). At maturity, except 1000-grain weight, major agronomic traits of ys53 were significantly affected. For instance, its plant height, number of productive panicles per plant, number of spikelets per panicle and seed-setting rate were significantly reduced by $18.5 \%, 21.0 \%, 20.4 \%$ and $8.9 \%$, respectively, compared with those of the wild type (Fig. 1d-h). In addition, because plant height of ys53 was significantly lower than that of the wild type, we measured its internode and panicle length. The results showed that each internode of ys53 was shortened proportionally, but its panicle length was not changed significantly (Additional file 2: Supplementary Fig. S1).

In order to further clarify the yellow phenotype of ys53, we determined photosynthetic pigment contents of the mutant and its wild type at different stages. At the seedling stage, contents of total chlorophyll (Chl), Chl $a$, Chl $b$ and carotenoids (Caro) in leaves of ys53 were significantly reduced by $61.0 \%, 59.5 \%, 66.1 \%$, and $30.0 \%$ respectively, compared with those in the wild-type leaves (Fig. 2a). At the booting stage, total Chl, Chl $a$, Chl $b$ and Caro contents in the mutant leaves were also significantly decreased by $55.7 \%, 58.0 \%, 46.5 \%$ and $28.3 \%$, respectively (Fig. 2b). These data suggested that the yellow leaf phenotype of ys53 was due to the defect in photosynthetic pigments.

To explore effect of the decreased pigment levels on the chloroplast structure of $y s 53$, the ultrastructure of chloroplasts was observed under a transmission electron microscope. In wild type, chloroplasts had intact thylakoid and granum structure, with dense and ordered grana stacks. In contrast, ys53 mutant chloroplasts had no intact thylakoid and granum structure, and exhibited obvious vacuolation (Fig. $2 \mathrm{c}$-f). The result indicated that the development of chloroplast was suppressed in the ys53 mutant. 

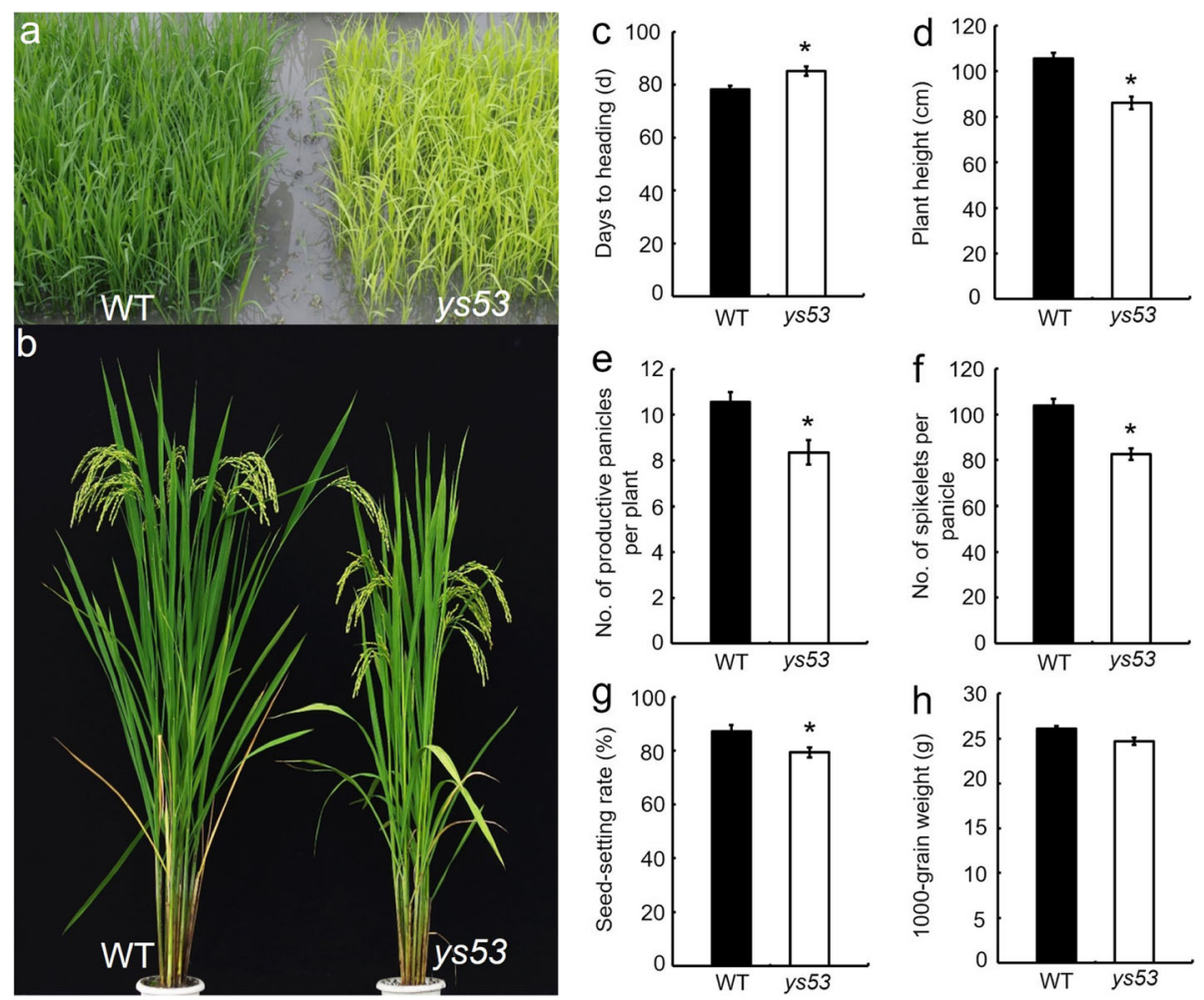

Fig. 1 Comparison of plant phenotypes and major agronomical traits of the ys53 mutant and its wild-type parent Nipponbare (WT). a Plant Phenotype at seedling stage. b Plant Phenotype at grain-filling stage. c Days to heading. $\mathbf{d}$ Plant height. e No. of productive panicles per plant. $\mathbf{f}$ No. of spikelets per panicle. $\mathbf{g}$ Seed-setting rate. $\mathbf{h}$ 1000-grain weight. Bars represent standard deviations (SDs) of three independent measurements. ${ }^{*}$ signify statistically significant differences compared to the wild type at $P<0.05$

Next, we investigated the photosynthetic capacity of ys53. As shown in Fig. $2 \mathrm{~g}$, net photosynthetic rate of the ys53 flag leaves at the grain-filling stage was significantly lower than that of the wild type, suggesting that decreased level of pigments and suppressed development of chloroplasts significantly affected the photosynthetic capacity of the $y s 53$ mutant.

In addition, to explore whether the yellow leaf phenotype of ys53 was affected by temperature, we treated ys53 and wild-type seedlings grown in the growth chamber using two different temperature conditions (constant $23^{\circ} \mathrm{C}$ and $30^{\circ} \mathrm{C}$ ), respectively. As a result, the ys53 mutant grown under different temperature conditions exhibited similar leaf-color phenotype and decrease degree of photosynthetic pigment contents (Additional file 2: Supplementary Fig. S2), which indicated that the yellow phenotype of ys53 was independent upon temperature.

\section{Map-Based Cloning of the ys53 Mutant Gene}

For genetic analysis of the mutant, ys53 was crossed with normal indica restorer line Minghui 63 . The resulting $\mathrm{F}_{1}$ plants exhibited a normal green phenotype, and leafcolor phenotypes of the $F_{2}$ population segregated with a ratio of $3: 1\left(\chi^{2}<\chi^{2}{ }_{0.05}=3.84, P>0.05\right.$, Additional file 1 :
Supplementary Table S1). The result suggested that the yellow leaf phenotype of the mutant was controlled by a single recessive nuclear gene. Then, SSR and InDel markers and the (ys53/Minghui 63) $\mathrm{F}_{2}$ population were used to map the mutant gene. The initial mapping result with $352 \mathrm{~F}_{2}$ yellow-leaf individuals showed that the target gene ys53 was linked to the SSR marker RM80 located on the long arm of Chromosome 8 (Fig. 3a). After that, the $852 \mathrm{~F}_{2}$ yellow-leaf plants and the seven InDel and SSR markers with polymorphism between the two parents were used to fine map the ys53 locus (Table 1). Finally, the target locus was narrowed to 102.5 -kb region between SSR marker RM502 and InDel marker YS6, at genetic distance of $0.6 \mathrm{cM}$ and $0.2 \mathrm{cM}$, respectively (Fig. 3b).

Within the above-mentioned 102.5 -kb region, 14 putative genes are annotated by Rice Genome Annotation Project (http://rice.plantbiology.msu.edu) (Fig. 3c, Additional file 1: Supplementary Table S2). Among these genes, only one gene (LOC_Os08g41990) contains a chloroplast transit peptide according to the analysis result using ChloroP and TargetP (http://www.cbs.dtu.dk/ services/ChloroP/; http://www.cbs.dtu.dk/services/ TargetP/). Meanwhile, 9 genes locating on the middle of this region were first amplified from ys53 genomic DNA 

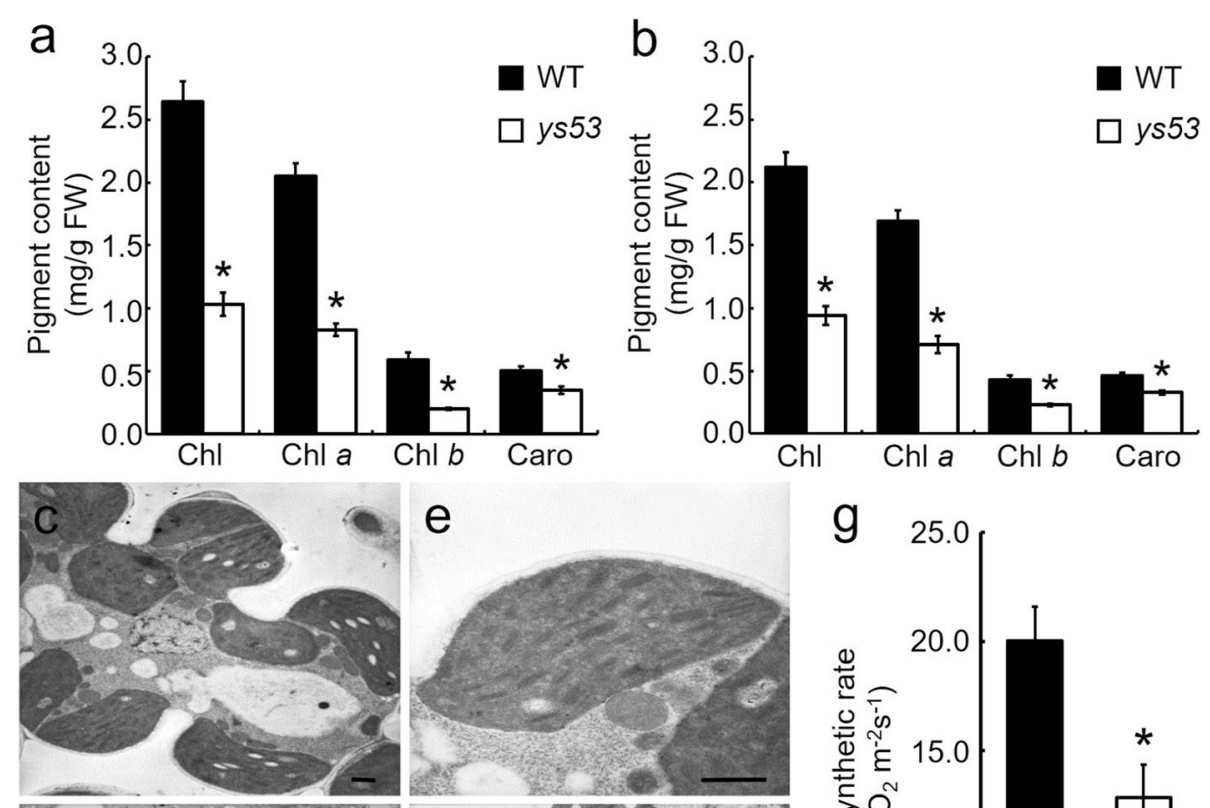

e
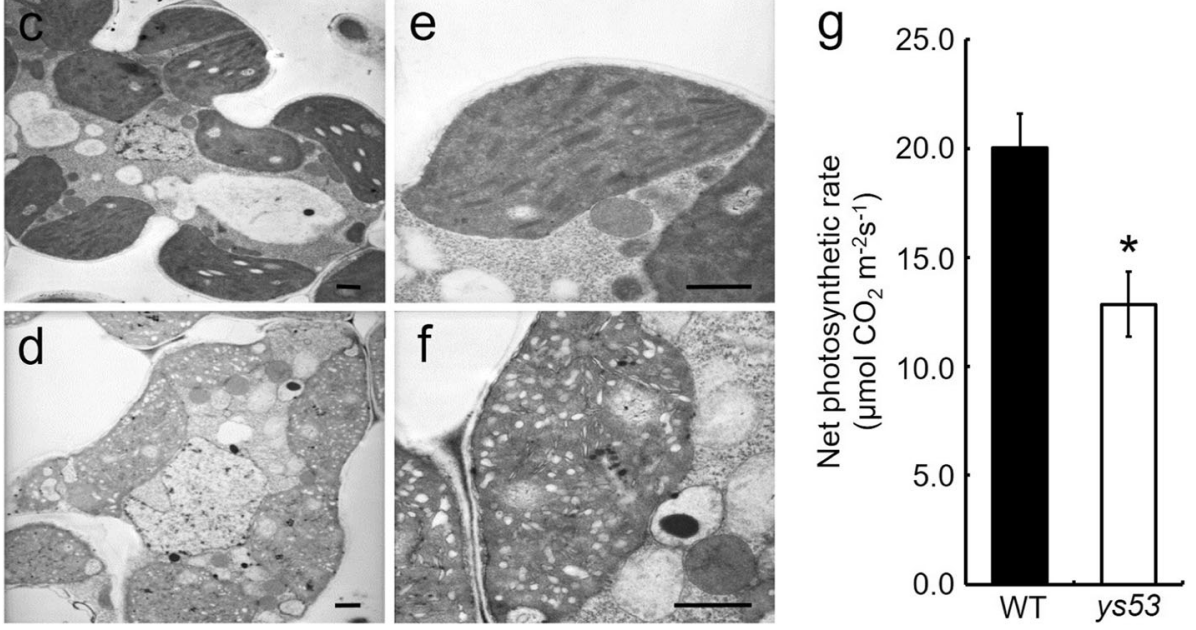

Fig. 2 Physiological characteristics of the ys53 mutant and its wild type. $\mathbf{a}$ and $\mathbf{b}$ Contents of photosynthetic pigments in leaves at seedling stage and booting stage, respectively. $\mathbf{c}$ and $\mathbf{d}$ Mesophyll cells of the wild type and ys53, respectively. $\mathbf{e}$ and $\mathbf{f}$ Chloroplasts of the wild type and ys53, respectively. $\mathbf{g}$ Net photosynthetic rate at grain-filling stages. Data are means \pm SD $(n=3)$. Error bars represent (SDs) standard deviations of three independent experiments. * indicate statistically significant differences compared to the wild type at $P<0.05$. Chl: chlorophyll. Caro: carotenoids. Scale bar $=1 \mu \mathrm{m}$

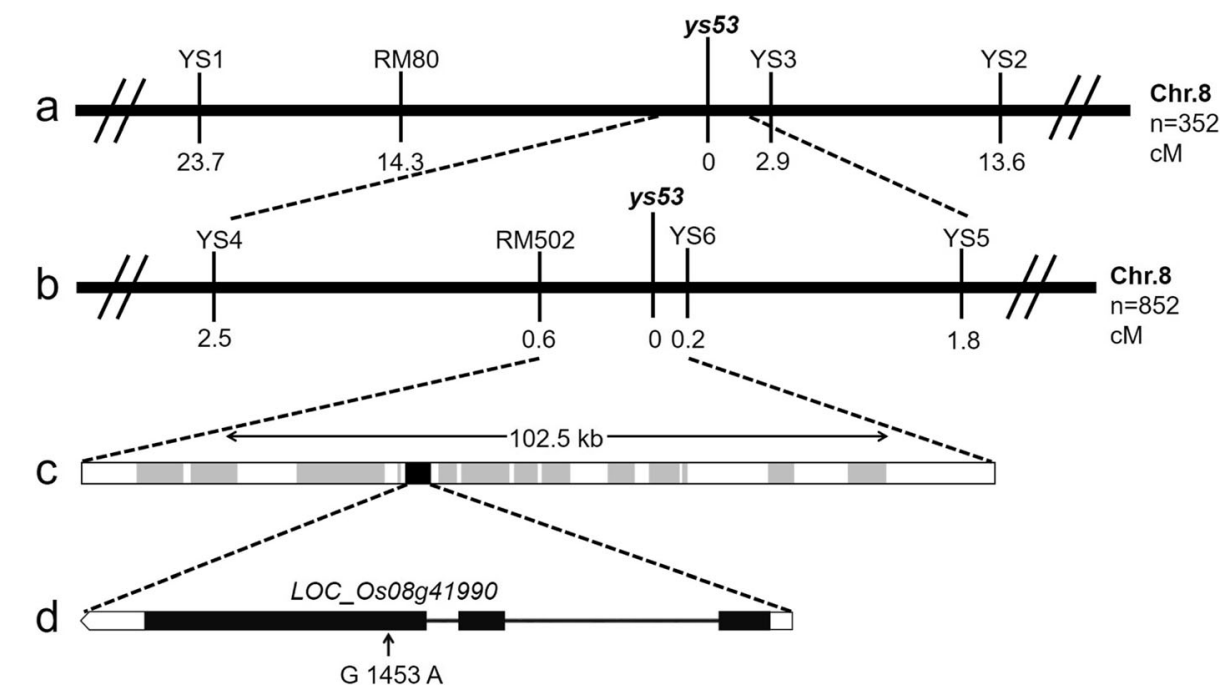

Fig. 3 Map-based cloning of the ys53 locus. a The ys53 locus was mapped to the long arm of rice chromosome 8 using $352 F_{2}$ yellow-leaf individuals. b This locus was further mapped to a 102.5-kb region between SSR marker RM502 and InDel marker YS6 using 852 F 2 yellow-leaf individuals. c This region contains 14 putative genes. d Candidate gene LOC_Os08g41990 comprises three exons and two introns, in which a single nucleotide G-to-A substitution occurred at position 1453 of its coding region in the mutant 
Table 1 Polymorphic InDel markers developed in this study

\begin{tabular}{|c|c|c|}
\hline Marker & Forward primer $\left(5^{\prime}-3^{\prime}\right)$ & Reverse primer $\left(5^{\prime}-3^{\prime}\right)$ \\
\hline YS1 & AGTATCATTTCGGTTTGGT & CATTCGTGGTTGTATTGG \\
\hline YS2 & TAGCCGATCCGAACTTGC & GTCTGACCTGCCGACCAA \\
\hline YS3 & TGGTGATGTCTAGCTCAATC & TGATAGGTGGATAGCAGT \\
\hline YS4 & ATGCCCGTGCTTCGGTAC & CTGTCATTGGAGACTTCG \\
\hline YS5 & GGACCTITACCCTGGCGC & GACGAGCTGGCACACATTC \\
\hline YS6 & GCTAGATTGCTCTCTGTGC & CTTGCAATTGACATTACC \\
\hline
\end{tabular}

and sequenced one by one (Additional file 1: Supplementary Table S3), and only one mutation was found and furthermore, occurred in the LOC_Os08g41990 gene in ys53 mutant. Then, we sequenced cDNA of this gene from ys53 mutant and its wild-type parent Nipponbare using reverse transcription (RT)-PCR, and confirmed the point mutation mentioned above. This gene encodes an aminotransferase with $78.9 \%$ and $75.7 \%$ identities to Arabidopsis GSA1 and GSA2 respectively, which participate in tetrapyrrole biosynthetic pathway in higher plants. In the ys53 mutant, a single nucleotide $\mathrm{G}$ to $\mathrm{A}$ substitution occurred at position 1453 of $L O C_{-}$ Os08g41990 genome sequence (corresponding to position 511 of its cDNA) (Fig. 3d), causing an amino acid change in its encoded protein. Therefore, $L O C_{-}$ Os08g41990 was considered as the candidate gene of ys53 mutant, and designated tentatively as OsGSAM.

Database searching showed that the OsGSAM gene is a single copy gene in rice genome. Sequencing revealed that this gene contains three exons and two introns. The full length of its genomic sequence is $2379 \mathrm{bp}$ and the cDNA length is $1437 \mathrm{bp}$. The protein encoded by OsGSAM consists of 478 amino acids and is predicted to have approximately $50 \mathrm{kDa}$ molecular weight. The OsGSAM protein contains two domains, a chloroplast transit peptide of 40 amino acid residues at $\mathrm{N}$-terminus and an aminotransferase class-III of 397 amino acid residues at C-terminus (Additional file 2: Supplementary Fig. S3) (http://smart.embl-heidelberg.de/). Meanwhile, it has 20 $\alpha$-helixes and $21 \beta$-sheets, and the mutation site in ys53 mutant was located on a conserved site of the 8th $\alpha$ helix (Additional file 2: Supplementary Fig. S3) (https:// swissmodel.expasy.org/interactive).

According to the multiple sequence alignment of OsGSAM and its homologues in different species, OsGSAM has a high similarity to its homologues in monocotyledonous plants, maize (Zea mays), and barley (Hordeum vulgare) and dicotyledonous plants, Arabidopsis thaliana (GSA2, GSA1), tobaco (Nicotiana attenuate) and cucumber (Cucumis satvus), with 92.2\%, 90.7\%, 78.9\%, $75.7 \%, 78.3 \%, 76.6 \%$ respectively. OsGSAM also has $76.6 \%$ and $73.4 \%$ similarity to its homologues in singlecelled algaes Chlamydomonas reinhardtii and Synechococcus, respectively. In addition, phylogenetic analysis showed that OsGSAM is more closely related to GSAM homologues from maize and barley than those from other species (Additional file 2: Supplementary Fig. S4).

\section{GSA Accumulation and ALA-Synthesis Ability in ys53 Mutant}

GSAM converts GSA to ALA by transferance of the amino group of GSA from $\mathrm{C} 2$ to $\mathrm{C} 1$ in higher plants (Tanaka and Tanaka 2007). If the ys53 mutant indeed has a defective GSAM, its ALA-synthesising capacity should be decreased, resulting in massive accumulation of GSA in the mutant plants. So we should first examine GSA content in ys53. However, GSA is an isomer of its product ALA, and both GSA and ALA can react with acetylacetone to form a pyrrole that further reacts with Ehrlich's reagent to form a colored compound. Then, we compared total content of GSA and ALA between ys53 and its wild type using the method of Mauzerall and Granick (1955) with slight optimization. The results showed that total content of GSA and ALA in ys53 mutant reached to $103.3 \mu \mathrm{g} / \mathrm{g}$.FW, but that in the wild type was only $3.9 \mu \mathrm{g} / \mathrm{g} \cdot \mathrm{FW}$ under natural condition (Fig. 4a). Generally, GSA is stable in dilute solution at acidic $\mathrm{pH}$ (such as the acidic condition in the present study) (Houen et al. 1983; Kannangara and Schouboe 1985). On the other hand, ALA is undetectable because it is very quickly converted to porphobilinogen by ALA dehydratase in normal plants (Richter et al. 2010). So the overwhelming majority of total content of GSA and ALA should actually be GSA content in ys53 mutant. Therefore, the data suggested that GSA massively accumulated in the mutant.

On the other hand, LA (levulinic acid) has a similar molecular structure to ALA and can compete with ALA to bind to ALA dehydratase, so excess LA can block the conversion of ALA to porphobilinogen. Therefore, we cultivated yellow seedlings of $y s 53$ and its wild type under light and excess LA conditions to compare ALAsynthesis capacity of them. As shown in Fig. 4b, the ALA-synthesis capacity of ys53 was $22.6 \mu \mathrm{g} / \mathrm{g} \cdot \mathrm{FW} \cdot \mathrm{h}$, while that of wild type was $39.4 \mu \mathrm{g} / \mathrm{g}$.FW.h, which showed that ALA-synthesis ability of the mutant was significantly reduced by $42.6 \%$ compared with that of the wild type.

Taken together, we concluded that GSAM protein should be defective in the $y s 53$ mutant.

\section{Complementation of the ys53 Mutant}

In order to further confirm that the yellow leaf phenotype of $y s 53$ was caused by the mutation in the OsGSAM gene, we constructed complementary vector and carried out transgenic experiment. First, the full-length cDNA of the wild-type OSGSAM gene was amplified, and inserted into the pCAMBIA2300 vector containing the 

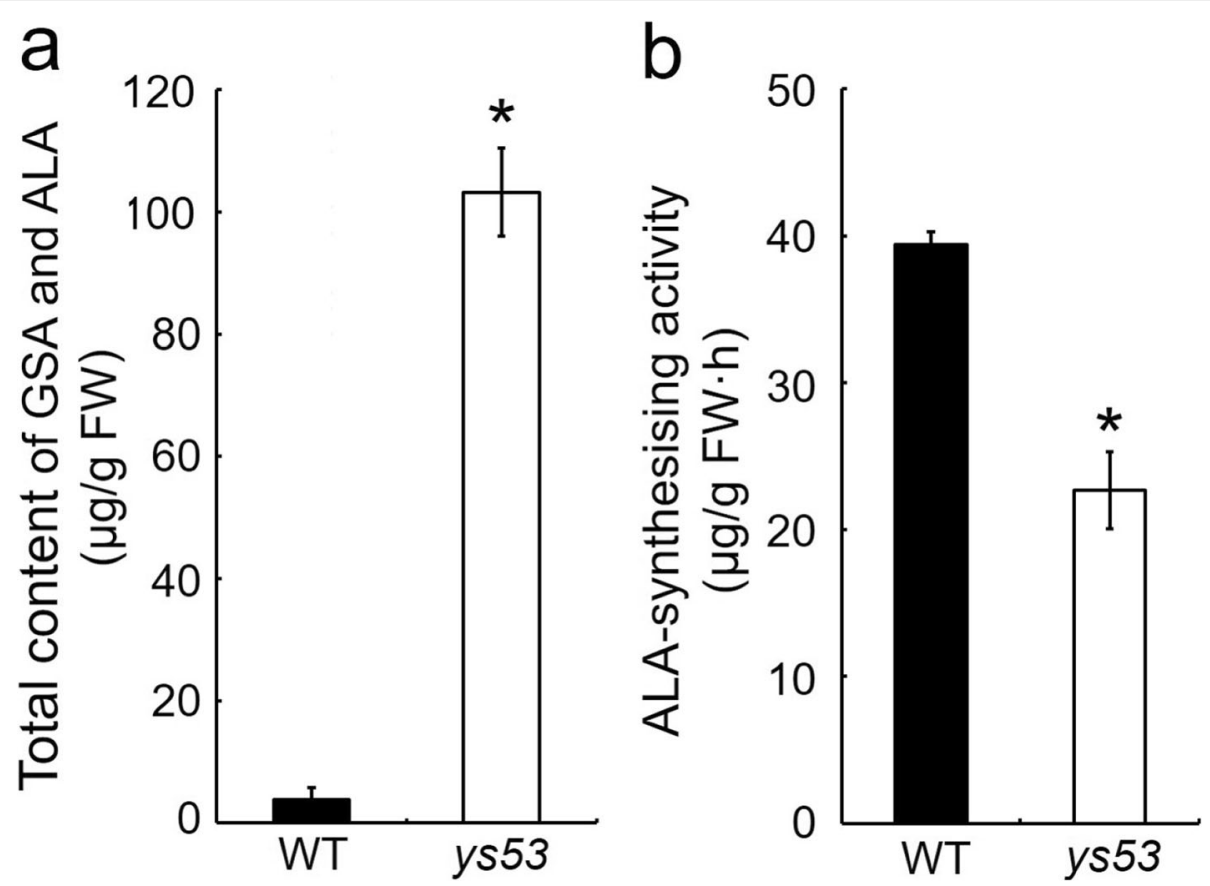

Fig. 4 Determination of GSA and ALA content and ALA-synthesizing activity in ys53 and its wild type. a Total content of GSA and ALA in rice leaves at seedling stage. Leaves were harvested from normal growing seedlings in the paddy field on sunny afternoons, quick freezed in liquid nitrogen and used for determination of total content of GSA and ALA. b ALA-synthesizing activity of rice seedlings. After 1 week of dark culture, the yellow seedlings of ys53 and its wild type were cultured under light condition $\left(100 \mu \mathrm{mol} \mathrm{m} \mathrm{m}^{-2} \mathrm{~s}^{-1}\right)$ for $7 \mathrm{~h}$ in LA (levulinic acid) solution, and then the measurement of GSA and ALA was performed. Error bars represent the SDs of three independent experiments. ${ }^{*}$ indicates statistically significant difference between ys53 and its wild type at $P<0.05$

Actin 1 promoter. Then, the fusion vector pCAMBIA2300-OsGSAM was introduced into the $y s 53$ mutant by Agrobacterium-mediated transformation. As a result, a total of 13 positive transgenic lines were obtained through identification with PCR (Fig. 5a). These transgenic lines all showed normal leaf-color phenotype as the wild type (Fig. 5b, c). Meanwhile, we measured pigment contents in the positive transgenic lines at seedling stage and booting stage, respectively. As shown in Fig. $5 \mathrm{~d}$ and e, pigment contents of transgenic lines TP-1, TP-2 and TP-3 were not significantly different from those of the wild type. In addition, we tested GSA accumulation and ALA-synthesis ability of TP-1, TP-2 and TP-3. The results showed that the three positive transgenic lines had significant increase of ALA-synthesis ability compared with ys53 mutant (Fig. 5f), and they had no obvious accumulation of GSA as the wild type (Fig. 5g). In a word, these data suggested that the OsG$S A M$ gene rescued the yellow leaf phenotype of ys53, confirming that the mutant phenotype was a consequent of the single-base mutation of OsGSAM gene.

\section{Subcellular Localization of OsGSAM Protein}

OsGSAM was predicted to be located in chloroplast because it contains a chloroplast transit peptide with 30 amino acid residues at its $\mathrm{N}$-terminus. To verify this prediction, we made pCAMBIA2300-35S-OsGSAM-GFP vector, a construct expressing the OsGSAM-GFP (green fluorescent protein) fusion protein, and transformed rice protoplast using the resulting construct and the empty vector pCAMBIA2300-35S-GFP (as control) respectively. Then, the transformed protoplasts were observed by laser-scanning confocal microscopy. As expected, the green fluorescence of OsGSAM-GFP fusion protein exactly overlapped with the red autofluorescence of chlorophyll in chloroplasts (Fig. 6a). Meanwhile, the green fluorescence of empty vector was diffusely distributed in the protoplast (Fig. 6b). This result suggested that OsGSAM is indeed located in chloroplast.

\section{Expression Pattern of OsGSAM Gene}

In order to explore the expression pattern of OsGSAM, its transcriptional levels in different tissues of the wild type were measured by qRT-PCR at the seedling stage and the booting stage, respectively. The data showed that OsGSAM was expressed in wide range of tissues, including roots, stems, leaf sheaths, leaf blades and young panicles. Nonetheless, OsGSAM was differentially expressed in different tissues. Specifically, leaf blades had the highest expression, followed by young panicles and leaf sheaths, while stems and roots had lower levels of expression (Fig. 7a). 

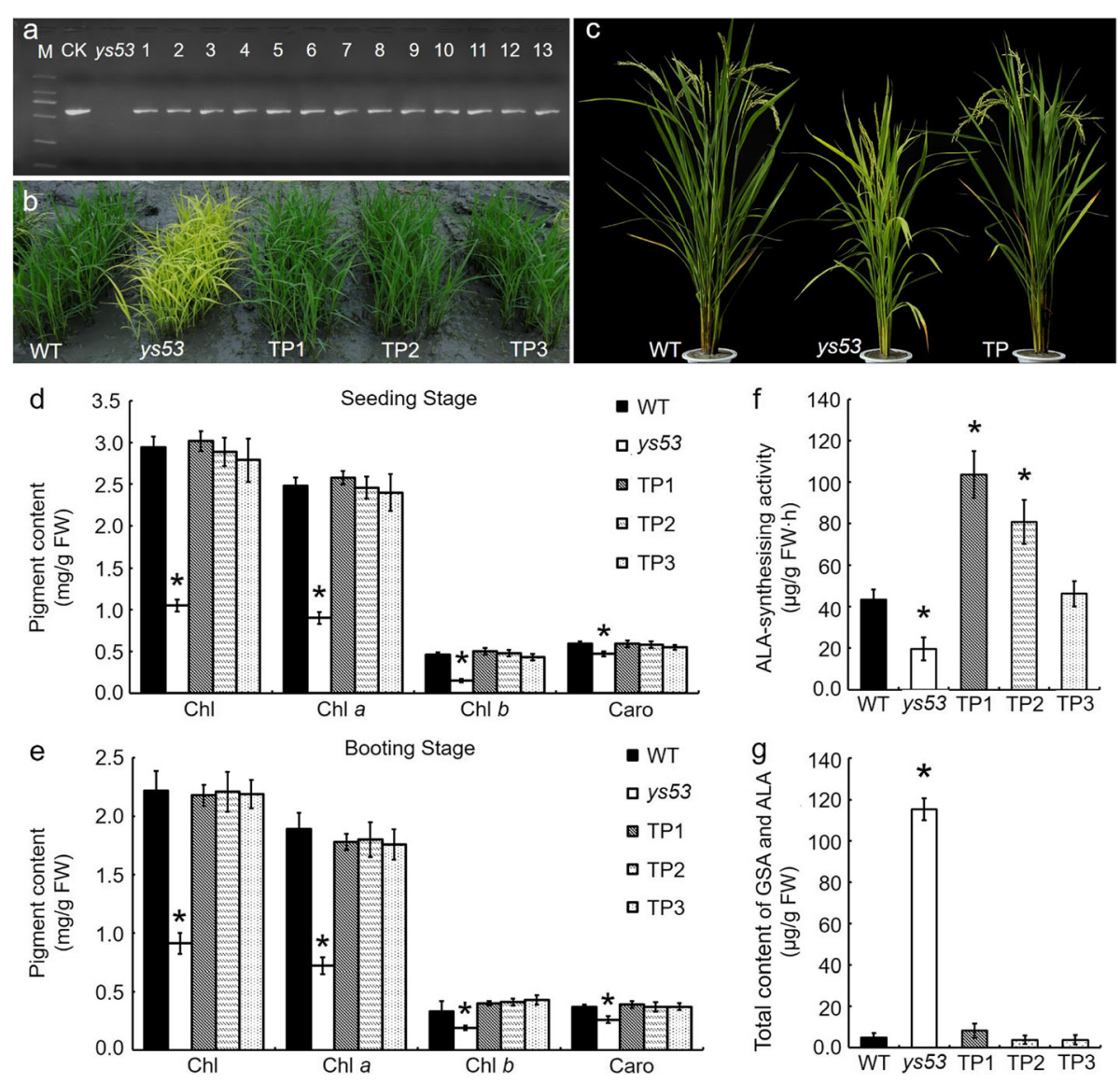

Fig. 5 Complementation of the ys53 mutant by OsGSAM gene. a Identification of transgenic lines by PCR. M, DL-2000 Marker; CK, pC2300-OsGSA plasmid (PCR positive control); ys53, ys53 mutant (PCR negative control); 1-13, positive transgenic plants. $\mathbf{b}$ Phenotypes of ys53 mutant, the wild type (WT), and the positive transgenic plants (TPs) at seedling stage. $\mathbf{c}$ Phenotypes of ys53, WT, and TPs at grain filling stage. $\mathbf{d}$ Photosynthetic pigment contents (in $\mathrm{mg} \mathrm{g}$ fresh weight ${ }^{-1}$ ) of $y s 53, \mathrm{WT}$, and TPs in leaves of four-week-old seedlings. e Photosynthetic pigment contents (in mg $\mathrm{g}$ fresh weight ${ }^{-1}$ ) in leaves of $y 553, \mathrm{WT}$, and TPs at booting stage. $\mathbf{f}$ and $\mathbf{g}$ ALA-synthesising activity of rice seedlings, and total content of GSA and ALA in rice leaves at seedling stage, respectively, which were detected according to the methods as Fig. 4. Data are mean \pm SD $(n=3)$. Error bars represent SDs of three independent experiments. ${ }^{*}$ indicate statistically significant differences compared with WT at $P<0.05$

\section{Expression Analysis of the Genes for Tetrapyrrole Biosynthesis and Photosynthesis}

Due to the contents of photosynthetic pigments and their precursor ALA in the ys53 mutant were significantly reduced, we examined transcription levels of the 14 genes involved in tetrapyrrole biosynthesis by qRTPCR at seedling stage. Among them, three genes encode the enzymes for the common steps of tetrapyrrole biosynthetic pathway, including glutamyl-tRNA reductase (GluTR, HEMA) (Apitz et al. 2016), GSAM, and 5aminolevulinate dehydratase (HEMB) (Tang et al. 2012); nine genes encode the enzymes for chlorophyll biosynthesis, including magnesium chelatase $\mathrm{D}$ subunit $(C H L D)$, chelatase $\mathrm{H}$ subunit $(C H L H)$, magnesium chelatase I subunit $(C H L I)$, magnesium chelatase $\mathrm{M}$ subunit (CHLM), Mg-protoporphyrin IX monomethylester cyclase (CHL27), 3,8-divinyl protochlorophyllide a 8-vinyl reductase $(D V R)$, protochlorophyllide oxidoreductase A
(PORA), Chl synthase (YGL1) and chlorophyllide $a$ oxygenase (CAO1) (Inagaki et al. 2015; Li et al. 2019; Kong et al. 2016; Wang et al. 2010; Sakuraba et al. 2013; Wu et al. 2007; Lee et al. 2005); and two genes encode ferrochelatase 1 and 2 ( $F C 1$ and $F C 2$ ) for the heme branch (Inagaki et al. 2015). As shown in Fig. 7b, all the three genes (HEMA, GSAM and HEMB) for the common steps were significantly down-regulated in the $y s 53$ mutant, compared with the wild type. In the 11 genes for chlorophyll and heme branches, only CHLH, CHL27 and YGL1 did not significantly change in expression level, and the other eight genes, including CHLD, CHLI, CHLM, DVR, $P O R A, C A O 1, F C 1$ and $F C 2$, were all significantly upregulated in the mutant.

Besides, the chloroplast development of ys53 mutant was suppressed, and its net photosynthetic rate was significantly decreased, so we also performed qRT-PCR to explore expression levels of the eight genes associated 


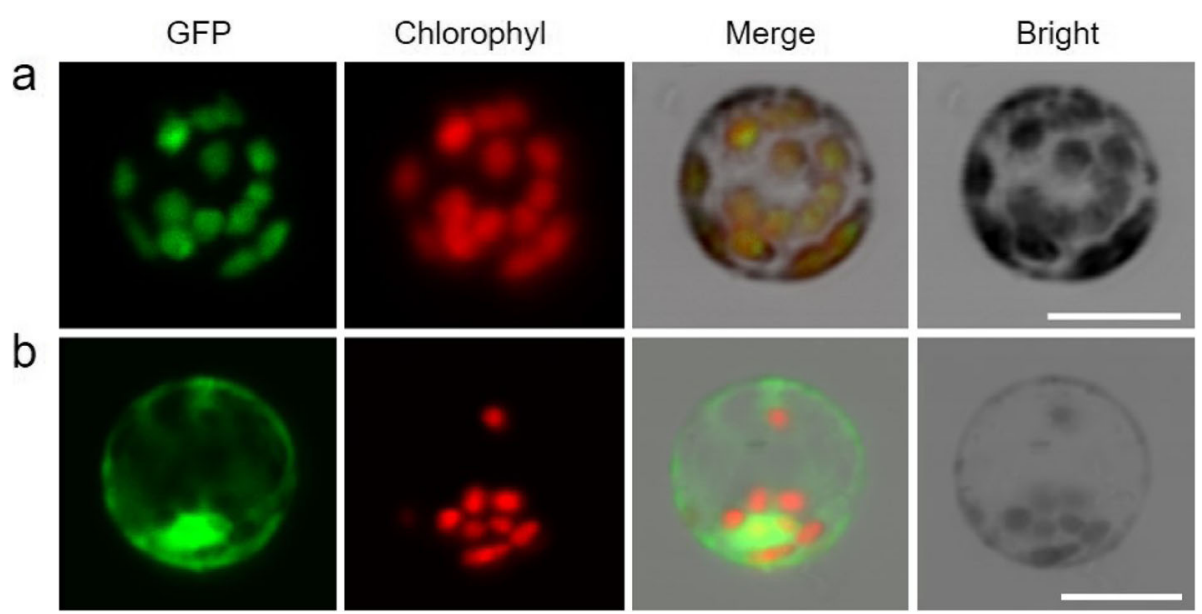

Fig. 6 Subcellular localization of OSGSAM protein. a GFP signals of the OsGSAM-eGFP fusion protein. $\mathbf{b}$ Empty vector eGFP without a specific targeting sequence. Green fluorescence shows GFP, red fluorescence indicates chloroplast autofluorescence, yellow fluorescence indicates images with the two types of fluorescence merged, and bright field images shows rice protoplasts. Fluorescence signals were visualized using a laserscanning confocal microscopy. Bars $=10 \mu \mathrm{m}$

with photosynthesis at seedling stage. The proteins encoded by these genes were as follows: rubisco small/ large subunit $(r b c S$ and $r b c L)$, two reaction center polypeptides $(p s a A$ and $p s b A)$ ), reaction center subunit of PSI $(p s a N)$, thylakoid luminal subunit of PSII ( $p s b P)$, and light-harvesting $\mathrm{Chl} a / b$-binding protein of PSII (CAB1R and $C A B 2 R$ ) (Li et al. 2015; Su et al. 2012; Amunts et al. 2010; Ifuku et al. 2008; $\mathrm{Ma}$ et al. 2017). The result showed that expression level of $p s b P$ did not significantly change, but those of the other seven genes were all significantly decreased in the mutant relative to those in the wild type (Fig. 7c).

The above data indicated that the mutation of OsG$S A M$ not only affected the expressions of tetrapyrrole biosynthetic genes, but also influenced those of photosynthetic genes in rice.

\section{Protein Interaction of OsGSAM with Itself}

GSAM protein was first found to exist as dimer in barley and Synechococcus (Grimm et al. 1989). To date, the dimers of GSAM were usually identified by $\mathrm{x}$-ray crystallography in many species, such as Escherichia coli, Synechococcus and Arabidopsis (Ilag et al. 1991; Hennig et al. 1997; Zhao et al. 2014). Here we carried out a series of yeast two-hybrid experiment to explore whether rice GSAM exists in the same form of dimer and where the dimeric protein was formed by interaction.

First, the full-length cDNA sequence of OsGSAM (FLcDNA) was fused to GAL4 AD and GAL4 BD vectors respectively, and the resulting constructs were cotransformed into $\mathrm{Y} 2 \mathrm{H}$ Gold yeast cells. The result showed that OsGSAM could interact with itself (Fig. 8b), which was consistent with the phenomenon of GSAM dimer in the previous reports.
Next, the FL-cDNA was divided into four different fragments encoding R1, R2, R3 and R4 peptide sequences, respectively (Fig. 8a). The four fragments were fused to GAL4 AD, and the resulting constructs were co-transferred with the GAL4 BD construct containing FL-cDNA into Y2H GOLD cells, respectively. The data showed that R1, R2 and R3 could interact with the fulllength GSAM protein, but R4 could not (Fig. 8c), implying that OsGSAM might contain two different interaction regions at its $\mathrm{N}$ - and $\mathrm{C}$-ends, respectively.

After that, the FL-cDNA was again divided into six different fragments encoding R5, R6, R7, R8, R9 and R10 peptide sequences, respectively (Fig. 8a). The six fragments were fused to GAL4 AD, and the resulting constructs were co-transferred with the GAL4 BD construct containing FL-cDNA into Y2H GOLD cells, respectively. As shown in Fig. 8d, R5, R6, R8 and R9 could interact with the full-length GSAM protein, but R7 and R10 could not. These results indicated that the interaction of OsGSAM with itself could largely depend on the two specific regions R8 and R9 which contain the 81th160th and the 321th-400th amino acid residues at the $\mathrm{N}$ - and C-terminals of OsGSAM, respectively.

\section{Discussion}

GSAM protein was first purified from barley and cyanobacteria Synechococcus using affinity chromatography and polyacrylamide gel electrophoresis under nondenaturing conditions (Grimm et al. 1989). So far, GSAM genes have only been identified via homology cloning strategy or RNA interference in many plant species, such as soybean (Sangwan and O'Brian 1993), tobacco (Höfgen et al. 1994; PöRs et al. 2001), tomato (Polking et al. 1995; Lytovchenko et al. 2011), and 

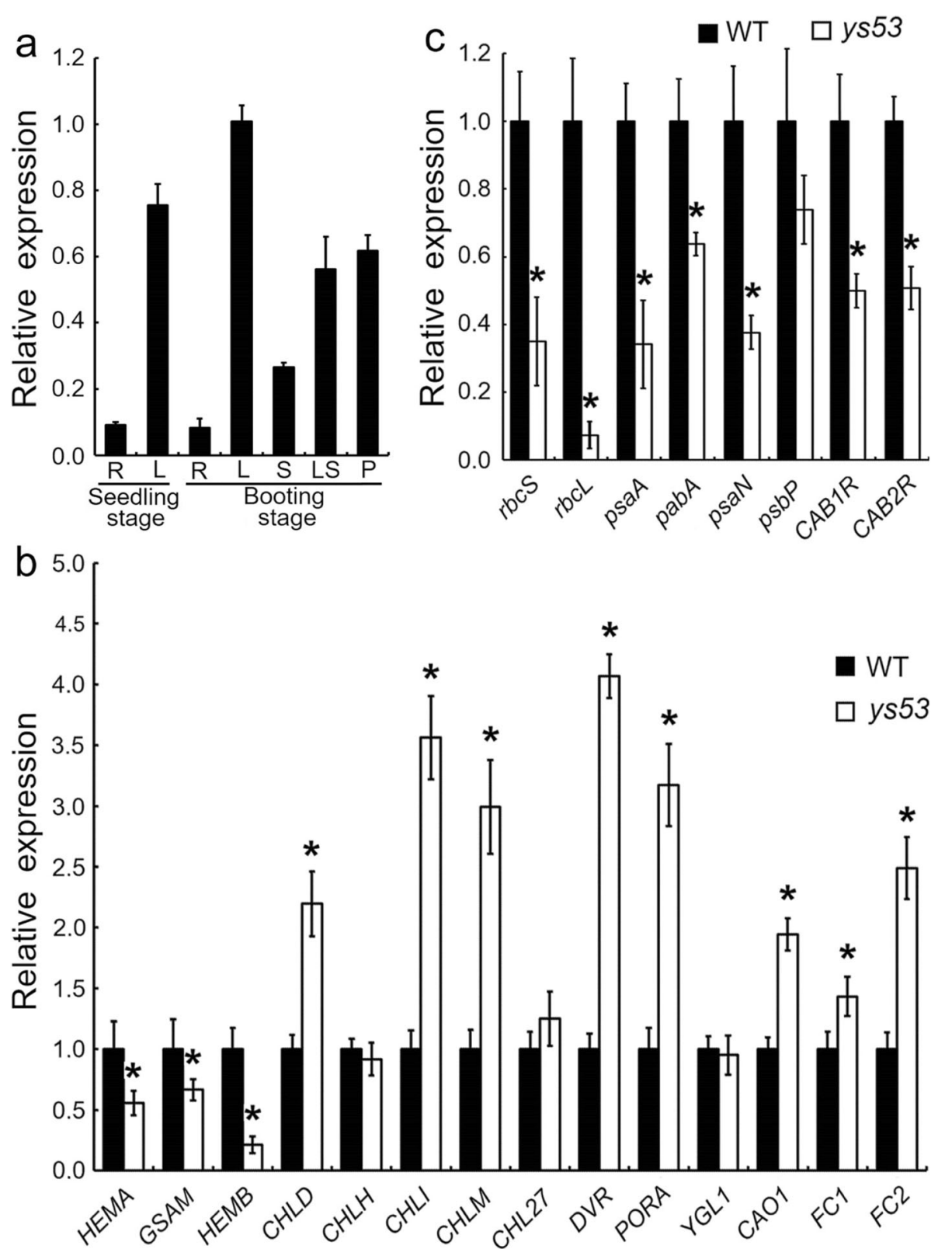

Fig. 7 Expression analyses of related genes by qRT-PCR. a Expression pattern of OsGSAM gene. The total RNA was extracted from different tissues, including root (R), leaf blade (L), stem (S), leaf sheath $(L S)$ and young panicle $(P)$, of the wild type at seedling stage and booting stage, respectively. Rice actin 1 gene was used as an internal control. Error bars represent the SDs of three independent experiments. $\mathbf{b}$ and $\mathbf{c}$ Comparison of expression levels of the genes associated with tetrapyrrole biosynthesis and photosynthesis, respectively, between ys53 and its wild at seedling stage. The total RNA was extracted from 4-week-old seedlings. The relative mRNA amount of each gene was normalized to Actin 1. The expression level of each gene in the wild type was set to 1.0, and those in ys53 mutant were calculated accordingly. Error bars represent the SDs of three independent experiments. Asterisks indicate statistically significant differences compared with the wild type at $P<0.05$

Brassica napus (Tsang et al. 2003a). However, no mutant of GSAM has been reported in monocotyledonous plants. In this study, a rice yellow-leaf mutant ys 53 was isolated, which showed a yellow phenotype, reduced contents of pigments, and impaired development of chloroplasts. Then, we cloned the OsGSAM gene by means of the ys53 mutant and map-based cloning approach, and found that a single nucleotide substitution occurred in the mutated gene of ys53, causing an amino acid change in its encoded protein. Furthermore, the yellow leaf phenotype of the mutant could be rescued by introducing the wild-type OSGSAM (Fig. 5). Therefore, we confirmed that the point mutation of OSGSAM was the cause of the yellow phenotype of this mutant, and 


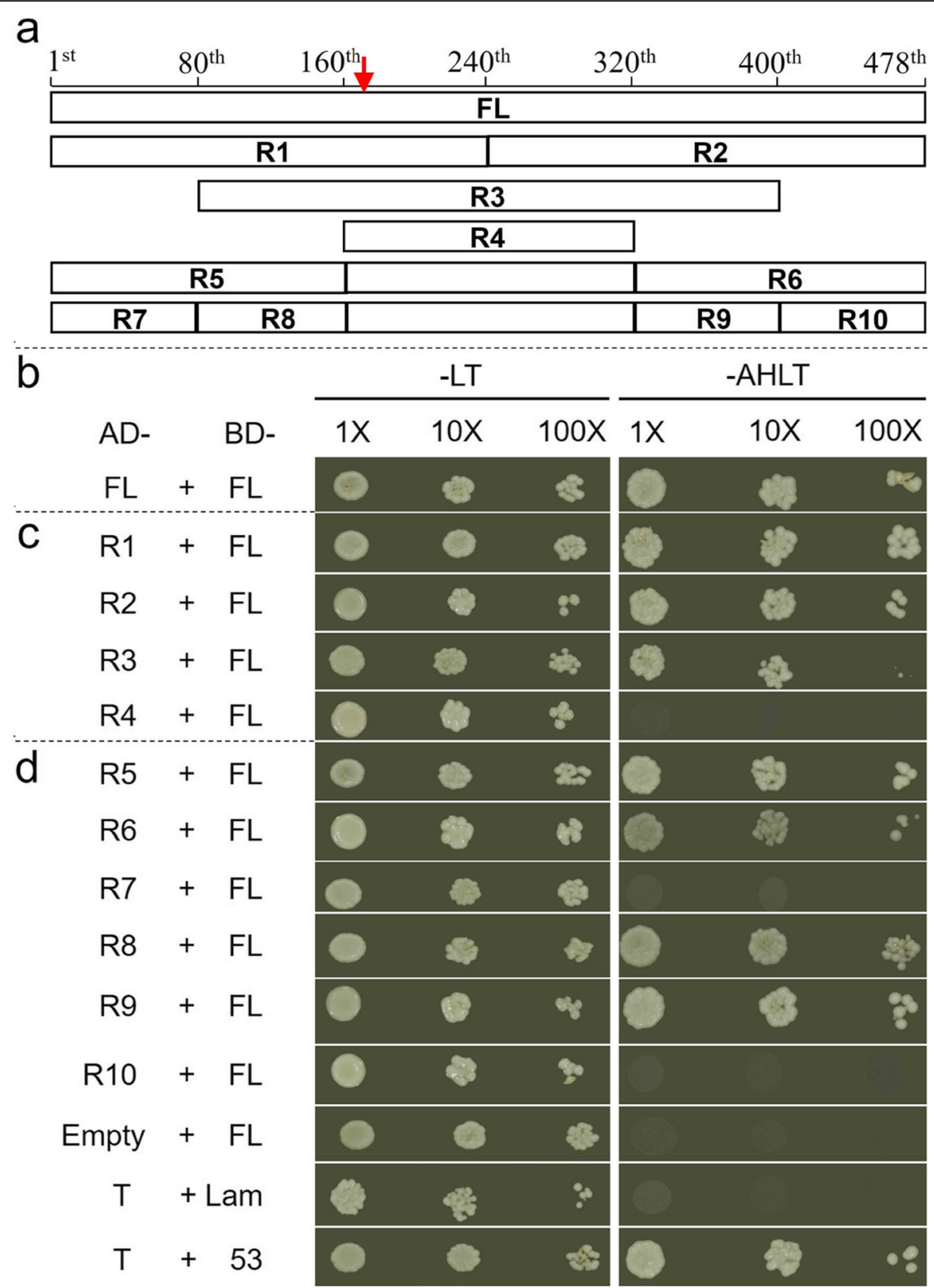

Fig. 8 OsGSAM protein truncation experiment. a Schematic diagram of OsGSAM protein truncation. FL represents the full-length OsGSAM, and R1-R10 correspond to truncated fragments containing the 1st-240th, 241th-478th, 81th-400th, 161th-320th, 1st-160th, 321th-478th, 1st-80th, 81th-160th, 321th-400th and 401th-478th amino acid residues of OSGSAM, respectively. The red arrow indicates the substitution of threonine for alanine at the 171th amino acid residue of OsGSAM in the ys53 mutant. b The yeast two-hybrid experiment of the full-length OsGSAM with itself. c Yeast two-hybrid experiments between the R1, R2, R3 and R4 fragments and the full-length GSAM. $\mathbf{d}$ Yeast two-hybrid experiments between the R5, R6, R7, R8, R9 and R10 fragments and the full-length GSAM. The FL was combined with empty pGADT7 vector as internal control. Interaction between pGADT7-T and pGBKT7-Lam was used as a negative control, and interaction between pGADT7-T and pGBKT7-53 was used as a positive control. Co-transformed yeast colonies were spotted on the selective SD medium minus Trp and Leu (-LT), the normally surviving monoclonal bacteria were selected and then dripped to the SD medium minus His, Leu, Trp and Ade to grow (-AHLT). 1X, 10X, and 100X represent the saturated culture solution of transformant diluted to concentrations of $1,0.1$ and 0.01 , respectively

successfully identified a GSAM gene in monocotyledonous plants through map-based cloning.

Up to now, a few of GSAM RNAi plants have been reported in higher plants. Among them, the GSAM RNAi plants of tabaco showed different degrees of chlorophyll reduction and variegation patterns (Höfgen et al. 1994). Brassica napus plants expressing a GSAM antisense gene directed by a Brassica napin promoter exhibited yellow 
cotyledons and a range of chlorophyll reduction in the seeds, but the seed growth and development were not affected (Tsang et al. 2003b). The tomato plants expressing antisense GSAM gene directed by TFM5 green fruitspecific promoter displayed lower chlorophyll levels and photosynthetic activity, but almost no differences in fruit size, weight, or ripening capacity (Lytovchenko et al. 2011). In this study, a single-base mutation of OsGSAM led to an amino acid substitution of the encoded protein, and finally caused yellow leaf phenotype throughout the whole growth period in ys53 mutant (Fig. 1a, b). Meanwhile, its pigment contents were reduced (Fig. 2a, b), chloroplast development was suppressed (Fig. 2c-f), and the net photosynthetic rate declined (Fig. $2 \mathrm{~g}$ ). In consequence, its plant height, number of productive panicles per plant, number of grains per panicle and seed setting rate were significantly reduced, but its grain weight was almost unchanged (Fig. 1d-g). The above phenotypes of ys53 were not completely consistent with the phenotypes of RNAi lines of tabaco, Brassica napus and tomato as previously reports, which could be due to the differences between a point mutation and RNA interferences and among the different plant species.

Structure investigations revealed that the Synechococcus GSAM protein contains four clusters of invariant residues, including (i) substrate binding residues (Ser29-Arg-32 and Glu-406), (ii) interface helix residues (Ser-122-Ala-126, Arg-132, and Arg-135), (iii) residues within the gating loop (Tyr-150-His-153, Leu-158, Ser163, and Thr-167), and (iv) residues fixing the phosphate group of cofactor of the opposite subunit (Tyr-301* Thr-305*) (Stetefeld et al. 2006). Each of the four clusters is conservative in different species, and involved in substrate binding, cofactor fixation, formation of the interface helix, or recruiting of the gating loop (Stetefeld et al. 2006). In the present study, the mutation site (the 171th amino acid residue) of ys53 is located on cluster (ii) of invariant residues (the interface helix residues), corresponding to Ala-126 of Synechococcus GSAM (Additional file 2: Supplementary Fig. S3). Therefore, we speculated that the mutation of Ala-171 to Thr could affect biological function of OsGSAM, resulting in significant reduction of ALA-synthesising capacity and the yellow leaf phenotype of the $y s 53$ mutant.

GSAM protein was first found to exist as a dimer in barley and Synechococcus (Grimm et al. 1989). However, almost all studies on the dimers and structures of GSAM were performed by $\mathrm{x}$-ray crystallography, for example, in E. coli (Ilag et al. 1991), cyanobacteria Synechococcus (Hennig et al. 1997; Stetefeld et al. 2006) and Arabidopsis (Zhao et al. 2014). So far, no other form of experimental evidence confirmed the dimeric phenomenon of this protein, and which region drives the formation of this dimer has not been reported. In the present study, we found that OsGSAM protein can interact with itself through yeast two-hybrid experiment (Fig. 8b), which is consistent with the phenomenon of GSAM dimer in the previous reports (Grimm 1990; Hennig et al. 1997; Contestabile et al. 2000; Stetefeld et al. 2006). Meanwhile, our further research indicated that the interaction of OsGSAM with itself could largely depend on the two specific regions R8 and R9 containing the 81th-160th and the 321th-400th amino acid residues at the $\mathrm{N}$ - and C-terminals of OsGSAM, respectively (Fig. 8c, d), which might be one aspect of the foundation leading to the formation of GSAM dimer.

\section{Conclusions}

YS53 encodes glutamate-1-semialdehyde 2,1-aminomutase (GSAM) participating in tetrapyrrole biosynthesis. In ys53 mutant, a single nucleotide substitution of YS53 gene causes massive accumulation of glutamate 1semialdehyde, leading to yellow leaf phenotype in rice. In addition, yeast two-hybrid experiment suggested that rice GSAM protein could interact with itself mainly by means of the two specific regions of amino acid residues at its $\mathrm{N}$ - and C-terminals, respectively.

\section{Materials and Methods \\ Plant Materials and Growth Conditions}

A yellow leaf mutant, ys53, was obtained from japonica cultivar Nipponbare through ethyl methanesulfonate (EMS) mutagenesis. The mutant was crossed with normal indica restorer line Minghui 63 to construct the $F_{1}$ and $F_{2}$ populations for genetic analysis and gene mapping. Rice materials were grown in a paddy field under the local growing environment in Wenjiang District (latitude $30^{\circ} 42^{\prime} \mathrm{N}$, longitude $103^{\circ} 50^{\prime} \mathrm{E}$ and altitude 539.3 m), Chengdu, Sichuan, China (Wang et al. 2010; Wang et al. 2014). In addition, to investigate effect of temperature on the phenotype of $y s 53$, rice seedlings were grown in the growth chamber under $12 \mathrm{~h}$ of light $\left(80-100 \mu \mathrm{mol} \mathrm{m}^{-2} \mathrm{~s}^{-1}\right) / 12 \mathrm{~h}$ of dark at constant $23^{\circ} \mathrm{C}$ (low temperature) or $30^{\circ} \mathrm{C}$ (high temperature) (Huang et al. 2017; Chen et al. 2013).

\section{Measurement of Photosynthetic Pigments}

Leaf samples were collected from ys53 and its wild type at seedling stage and booting stage respectively. $0.2 \mathrm{~g}$ leaf was used to extract pigments with $80 \%$ acetone at $4{ }^{\circ} \mathrm{C}$ for $48 \mathrm{~h}$ under dark condition. Then, contents of chlorophylls (Chl) and carotenoids (Caro) were measured using a BIOMATE 35 UV-Visible Spectrophotometer (Thermo Scientific) at $470 \mathrm{~nm}, 646 \mathrm{~nm}$ and $663 \mathrm{~nm}$, and were calculated according to the method of Lichtenthaler and Wellburn (1983). The pigment data of each sample were measured for three independent experiment repeats. 


\section{Measurement of Net Photosynthetic Rate}

Net photosynthetic rate $(\mathrm{Pn})$ was measured under 400 $\mathrm{ppm}$ of $\mathrm{CO}_{2}$ concentration and sunny weather condition, during 09:30-10:30 a.m. when the solar radiation was approximately $1200 \mu \mathrm{mol} \mathrm{m}^{-2} \mathrm{~s}^{-1}$. During grain-filling stage, the flag leaves of wild type and ys53 mutant was selected to measure the photosynthetic capability with a portable photosynthetic apparatus (Li-6400, Li-COR Inc., USA) (Sun et al. 2012).

\section{Map-Based Cloning and Marker Development}

Eight hundred fifty-two recessive plants which showed yellow-leaf phenotype were selected from the (ys53/Minghui 63) $F_{2}$ segregating population. The whole genome DNA of $y s 53$, Minghui 63 and these recessive plants were separately extracted for the linkage mapping analysis based on simple sequence repeat (SSR) markers. The SSR markers used were filtered from the Gramene database (http://archive.gramene.org/markers/microsat/) of the SSR linkage map constructed by McCouch et al. (2002). For fine mapping, the insertion/deletion (InDel) markers were selected, which were based on the flanking sequence that contains natural difference of $25-75 \mathrm{bp}$ of gap between japonica rice cv Nipponbare and indica rice cv 9311 in the multiple sequence alignment, and designed by Primer 5.0. All BLAST searches of the markers were performed by using National Center for Biotechnology Information database (http://www.ncbi.nlm.nih. gov/BLAST/).

\section{Transmission Electron Microscopy Analysis}

The fully expanding leaves were harvested from the $y s 53$ mutant and its wild type Nipponbare at the three-leaf stage. The selected leaf tissues were fixed by soaking in a phosphate buffer containing 3\% glutaraldehyde and then fixed again with $1 \%$ osmium dioxide. Next, the sample was gradually dehydrated, embedded, sectioned, and stained. Finally, submicroscopic structure of the sample was observed by transmission electron microscopy ( $\mathrm{H}-$ 600IV, Hitachi) (Wang et al. 2010).

\section{Sequence Analysis}

The full-length cDNA and amino acid sequences of OsGSAM and its homologues were acquired from GeneBank (http://www.ncbi.nlm.nih.gov). The chloroplast signal peptide was predicted according to http://www.cbs. dtu.dk/services/TargetP (Emanuelsson et al. 2007). Multiple sequence alignment was performed using DNAM AN version 6.0 (Lynnon Biosoft). The phylogenetic tree was constructed using the program MEGA 7.0 (Mega Limited) and the maximum likelihood algorithm.

\section{Determination of ALA and GSA Contents and ALA- Synthesis Ability}

In order to measure total contents of ALA and GSA under natural condition, the fresh leaves of rice were collected from normal growing plants at seedling stage in the paddy field on sunny afternoons, and immediately stored in liquid nitrogen environment. The detection of ALA and GSA contents was performed according to the protocol of Mauzerall and Granick (1955) with slight optimization. First, the leaf tissues were homogenated adequately in $5 \mathrm{ml}$ of $4 \%$ trichloroacetic acid (TCA, PH 1.0). After centrifugation for $5 \mathrm{~min}$ at $8000 \mathrm{r} / \mathrm{min}$ and $4{ }^{\circ} \mathrm{C}, 1 \mathrm{~mL}$ of the extraction solution was taken into a new tube, and $500 \mu \mathrm{L} 1 \mathrm{M} \mathrm{NaAc}$ and $50 \mu \mathrm{L}$ acetylacetone were added into this tube. Then, the mixed reaction solution in the tube was cooled to room temperature after $10 \mathrm{~min}$ in a boiling water bath and centrifuged at $8000 \mathrm{r} /$ min for $5 \mathrm{~min}$. Subsequently, $1.0 \mathrm{ml}$ of the supernatant was taken in another new tube, and an equal volume of Ehrlich's reagent was added into this tube for reaction under dark condition for $10 \mathrm{~min}$. Finally, the absorbance of the sample was measured at $553 \mathrm{~nm}$, and the ALA and GSA concentration can be obtained according to the standard curve.

For the determination of ALA-synthesising activity, the four steps, including acquisition of yellow seedlings, accumulation, extraction and determination of ALA, were successively carried out. First, the acquisition of yellow seedlings and accumulation of ALA were performed according to the method described previously (Beale 1970; Aarti et al. 2007) with a slight modification. Seeds of ys53 and its wild type were cultivated for 1 week in the dark, and $0.4 \mathrm{~g}$ young leaf tissues were harvested and immersed into $100 \mathrm{ml}$ of $20 \mathrm{mM}$ LA (levulinic acid) solution under $7 \mathrm{~h}$ of light $\left(100 \mu \mathrm{mol} \mathrm{m}^{-2} \mathrm{~s}^{-1}\right)$ for ALA accumulation. Then, the leaf tissues were homogenated adequately in $5 \mathrm{ml}$ of $50 \mathrm{mM}$ phosphate buffer (pH 6.8). Subsequently, extraction and determination of ALA are performed using the above-mentioned method.

\section{Complementation Analysis}

For complementation of $y 553$, the full-length cDNA sequence (1437 bp) of OsGSAM (LOC_Os08g41990) was amplified from the wild-type Nipponbare using a pair of primers 5'-GAGTCTAGAATGGCCGGAGCAGCAGC C-3' and 5' -TCGCTGCAGCTATATCCGGCGAAGAA C-3', which have a $X b a \mathrm{I}$ site at $5^{\prime}$-end and a PstI site at $3^{\prime}$-end of this gene respectively. After digested with enzymes $X b a \mathrm{I}$ and PstI, the PCR product was ligated into the binary vector pCAMBIA2300. The constructed pCAMBIA2300-OsGSAM vector, which contained the target OsGSAM gene driven by the Actin 1 promoter, was transferred into the $y s 53$ mutant by Agrobacterium 
tumefaciens-mediated transformation. Transgenic plants were detected by a pair of primers 5'-CTTATG GTGGGGCTCAAG-3' and 5'-GCGATCATAGGCGT CTCG-3' which located on the OsGSAM gene and the pCAMBIA2300 vector respectively (Additional file 1: Supplementary Table S5).

\section{Subcellular Localization}

The full-length cDNA fragment of OsGSAM was amplified from the wild type and inserted into pCAMBIA2300-35S-eGFP vector. The PCR primers were 5'-GAGGGATCCATGGCCGGAGCAGCAGCC$3^{\prime}$ and $5^{\prime}$-TCGTCTAGACTCTATCCGGCGAAGAAC$3^{\prime}$, which contained a $\mathrm{BamHI}$ site at the $5^{\prime}$-end and a $X b a \mathrm{I}$ site at the $3^{\prime}$-end of the cDNA fragment respectively (Additional file 1: Supplementary Table S5). The constructed fusion vector pCAMBIA2300-35S-OsGSAM-eGFP and the empty vector pCAMBIA2300-35SeGFP (negative control) were transformed into the rice protoplasts respectively, following the method as previously described (Zhang et al. 2011). Finally, the GFP fluorescence in the transformed protoplasts was examined under a laser-scanning confocal microscopy (Nikon A1).

\section{qRT-PCR Analysis}

The roots, stems, leaf sheaths, leaf blades and young panicles of rice in different stages were harvested from the naturally growing plants of ys53 and its wild type in the field at early morning, and the total RNA was extracted with RNA extraction kit (Vazyme). The first strand of cDNA is reversed-transcribed from total RNA $(2 \mu \mathrm{g})$ using a reverse transcription kit (Vazyme) according to the manufacturer's instructions. The primer pair qGSAM-1F (5'-TGGACGTAAGGACATCAT-3') and qGSAM-1R (5'-GTCCAAGTAATCGTAGGT-3') were used to quantify the OsGSAM expression levels of the various samples to describe the expression pattern of the gene. To measure the relative expression of the genes associated with tetrapyrrole biosynthesis and photosynthesis, 22 pairs of primers were developed. Real-time quantitative PCR (qRT-PCR) was performed in a total volume of $10 \mu \mathrm{L}$ containing $0.2 \mu \mathrm{M}$ of each primer pairs and $1 \times$ SYBR green PCR master mix (Vazyme) by using the CFX96 real-time PCR system (Bio-Rad). All reaction conditions were as follows: $95^{\circ} \mathrm{C}$ for $5 \mathrm{~min}$, then 40 cycles of $95^{\circ} \mathrm{C}$ for $10 \mathrm{~s}$ and $58^{\circ} \mathrm{C}$ for $30 \mathrm{~s}$. For each experimental group, qRT-PCR was operated with three technical replicates for each of three biological replicates. The $2^{-\triangle \Delta C T}$ method was applied to calculate the quantitative expression of each genes relative to the internal control. The Actin 1 gene was used for normalization as an internal control. All qRT-PCR primers were listed in Additional file 1: Supplementary Table S4.

\section{Yeast Two Hybrid Assay}

The Matchmaker GAL4 two-hybrid system 3 of Clontech (Clontech, USA) was used. The full-length cDNA and a series of truncated cDNA sequences of OsGSAM gene were amplified and inserted into pGADT7 and pGBKT7 vectors respectively, and the BamHI site in the vectors was chosen as the insertion site for all sequences. The self-activation was tested by the bait construct fused with $\mathrm{BD}$. The combination containing the self-activating fusion vector was supplemented with $30 \mathrm{mM}$ 3-AT (3amino-1,2,4-triazole) in its corresponding medium. The above recombinant vectors were combined according to experimental needs, and then co-transformed into the yeast strain Y2HGold cells. Each transformant was spotted on non-selective (-Leu/-Trp) plates for $3 \mathrm{~d}$ at $28^{\circ} \mathrm{C}$, and tested for the protein interaction by observing their growth situation on selective (-Ade/-His/-Leu/-Trp) plates. The saturated culture solution of each transformant was diluted to concentrations of $1,0.1$ and 0.01 , and dripped onto its corresponding plates. Interaction between pGADT7-T and pGBKT7-Lam was used as a negative control, and interaction between pGADT7-T and pGBKT7-53 was used as a positive control. The pGBKT7 vector fused with full-length cDNA sequence was combined with empty pGADAD vecter as internal control. Primer sets used for generating constructs were listed in Additional file 1: Supplementary Table S6.

\section{Abbreviations}

ALA: 5-aminolevulinic acid; GSA: Glutamate 1-semialdehyde; GSAM: Glutamate 1-semialdehyde 2,1-aminomutase; Chl: Chlorophyll; GFP: Green fluorescent protein; Y2H: Yeast two hybrid

\section{Supplementary Information}

The online version contains supplementary material available at https://doi. org/10.1186/s12284-021-00492-x.

Additional file 1: Table S1. Segregation of $F_{2}$ population from the cross between ys53 and normal green leaf variety. Table S2. Putative genes within the 102.5-kb region. Table S3. The sequenced genes and corresponding PCR amplification primers in the fine mapping region. Table S4. Primers used in qRT-PCR. Table S5. Primers used in vector construction for complementation and subcellular localization. Table S6. Primers used in OsGSAM truncation experiment.

Additional file 2: Fig. S1. Internode length of ys53 and its wild type. Fig. S2. Temperature treatment of the ys53 mutant and its wild type. Fig. S3. Sequence alignment of OsGSAM and its homologues. Fig. S4. Phylogenetic analysis of OsGSAM and its homologs. Fig. S5. Tetrapyrrole biosynthetic pathway in higher plants.

\section{Acknowledgements}

Not applicable.

\section{Authors' Contributions}

QW and BZ performed most of the research. YL and SW assisted in the determination of intermediate products. JG and XY carried out subcellular 
localization assays, CC, ZY, QL and BY assisted in some field experiments, and CS provided technical assistance. QW and XD analyzed the experimental data and drafted the manuscript. PW and XD designed the experiments, supervised the study and revised the manuscript. All authors read and approved the manuscript.

\section{Funding}

This study was supported by the National Natural Science Foundation of China (31971869) and the National Key Research and Development Program of China (2017YFD0100201).

\section{Availability of Data and Materials}

All data generated or analyzed during this study are included in this article (and its supplementary information files).

\section{Declarations}

\section{Ethics Approval and Consent to Participate}

Not applicable.

\section{Consent for Publication}

Not applicable.

\section{Competing Interests}

The authors declare no potential competing interests.

\section{Author details}

${ }^{1}$ State Key Laboratory of Crop Gene Exploration and Utilization in Southwest China, Sichuan Agricultural University, Chengdu 611130, China. ${ }^{2}$ Rice Research Institute, Sichuan Agricultural University, Chengdu 611130, China.

Received: 10 March 2021 Accepted: 12 May 2021

Published online: 05 June 2021

\section{References}

Aarti D, Tanaka R, Ito H, Tanaka A (2007) High light inhibits chlorophyll biosynthesis at the level of 5-aminolevulinate synthesis during de-yellow in cucumber (Cucumis sativus) cotyledons. Photochem Photobiol 83(1):171-176. https://doi.org/10.1562/2006-03-06-RA-835

Amunts A, Toporik H, Borovikova A, Nelson N (2010) Structure determination and improved model of plant photosystem I. J Biol Chem 285(5):3478-3486. https://doi.org/10.1074/jbc.M109.072645

Apitz J, Nishimura K, Schmied J, Wolf A, Hedtke B, van Wijk KJ, Grimm B (2016) Posttranslational control of ALA synthesis includes GluTR degradation by Clp protease and stabilization by GluTR-binding protein. Plant Physiol 170(4): 2040-2051. https://doi.org/10.1104/pp.15.01945

Beale SI (1970) The biosynthesis of $\delta$-aminolevulinic acid in chlorella. Plant Physiol 45(4):504-506. https://doi.org/10.1104/pp.45.4.504

Chen H, Cheng ZJ, Ma XD, Wu H, Liu YL, Zhou KN, Chen YL, Ma WW, Bi JC, Zhang $X$, Guo XP, Wang JL, Lei CL, Wu FQ, Lin QB, Liu YQ, Liu LL, Jiang L (2013) A knockdown mutation of YELLOW-GREEN LEAF2 blocks chlorophyll biosynthesis in rice. Plant Cell Rep 32(12):1855-1867. https://doi.org/10.1007/ s00299-013-1498-y

Contestabile R, Angelaccio S, Maytum R, Bossa F, John RA (2000) The contribution of a conformationally mobile, active site loop to the reaction catalyzed by glutamate semialdehyde aminomutase. J Biol Chem 275(6): 3879-3886. https://doi.org/10.1074/jbc.275.6.3879

Emanuelsson O, Brunak S, von Heijne G, Nielsen H (2007) Locating proteins in the cell using TargetP, SignalP and related tools. Nat Protoc 2(4):953-971. https://doi.org/10.1038/nprot.2007.131

Ge HH, Lv XH, Fan J, Gao YX, Teng MK, Niu LW (2010) Crystal structure of glutamate 1-semialdehyde aminotransferase from Bacillus subtilis with bound pyridoxamine-5'-phosphate. Biochem Biophys Res Commun 402(2):356-360. https://doi.org/10.1016/j.bbrc.2010.10.033

Grimm B (1990) Primary structure of a key enzyme in plant tetrapyrrole synthesis: glutamate 1-semialdehyde aminotransferase. Proc Natl Acad Sci U S A 87(11): 4169-4173. https://doi.org/10.1073/pnas.87.11.4169

Grimm B, Bull A, Welinder KG, Gough SP, Kannangara CG (1989) Purification and partial amino acid sequence of the glutamate 1-semialdehyde aminotransferase of barley and synechococcus. Carlsb Res Commun 54(2): 67-79. https://doi.org/10.1007/BF02907586
Grimm B, Smith AJ, Kannangara CG, Smith M (1991) Gabaculine-resistant glutamate 1-semialdehyde aminotransferase of Synechococcus. Deletion of a tripeptide close to the $\mathrm{NH}_{2}$ terminus and internal amino acid substitution. J Biol Chem 266(19):12495-12501. https://doi.org/10.1016/ S0021-9258(18)98926-X

Hennig M, Grimm B, Contestabile R, John RA, Jansonius JN (1997) Crystal structure of glutamate 1-semialdehyde aminomutase: an $\mathrm{a}_{2}$-dimeric vitamin $\mathrm{B}_{6}$-dependent enzyme with asymmetry in structure and active site reactivity. Proc Natl Acad Sci U S A 94(10):4866-4871. https://doi. org/10.1073/pnas.94.10.4866

Höfgen R, Axelsen KB, Kannangara CG, Schüttke I, Pohlenz HD, Willmitzer L, Grimm B, von Wettstein D (1994) A visible marker for antisense mRNA expression in plants: inhibition of chlorophyll synthesis with a glutamate 1semialdehyde aminotransferase antisense gene. Proc Natl Acad Sci U S A 91(5):1726-1730. https://doi.org/10.1073/pnas.91.5.1726

Houen G, Gough SP, Kannangara CG (1983) $\Delta$-aminolevulinate synthesis in greening barley v. the structure of glutamate 1-semialdehyde. Carlsb Res Commun 48(6):567-572. https://doi.org/10.1007/BF02907558

Huang R, Wang Y, Wang PR, Li CM, Xiao FL, Chen NG, Li N, Li CX, Sun CH, Li LH, Chen RJ, Xu ZJ, Zhu JQ, Deng XJ (2017) A single nucleotide mutation of IspF gene involved in the MEP pathway for isoprenoid biosynthesis causes yellow-green leaf phenotype in rice. Plant Mol Biol 96:5-16

Ifuku K, Ishihara S, Shimamoto R, Ido K, Sato F (2008) Structure, function and evolution of the PsbP protein family in higher plants. Photosynth Res 98(1-3): 427-437. https://doi.org/10.1007/s11120-008-9359-1

llag LL, Jahn D, Eggertsson G, Söll D (1991) The Escherichia coli hemL gene encodes glutamate 1-semialdehyde aminotransferase. J Bacteriol 173(11): 3408-3413. https://doi.org/10.1128/JB.173.11.3408-3413.1991

llag LL, Kumar AM, Söll D (1994) Light regulation of chlorophyll biosynthesis at the level of 5-aminolevulinate formation in Arabidopsis. Plant Cell 6(2):265275. https://doi.org/10.1105/tpc.6.2.265

Inagaki N, Kinoshita K, Kagawa T, Tanaka A, Ueno O, Shimada H, Takano M (2015) Phytochrome B mediates the regulation of chlorophyll biosynthesis through transcriptional regulation of ChIH and GUN4 in rice seedlings. PLoS One 10(8):e0135408. https://doi.org/10.1371/journal.pone.0135408

Kannangara CG, Schouboe A (1985) Biosynthesis of $\Delta$-aminolevulinate in greening barley leaves. VII. Glutamate 1-semialdehyde accumulation in gabaculine treated leaves. Carlsb Res Commun 50(3):179-191. https://doi. org/10.1007/BF02907144

Kong WY, Yu XW, Chen HY, Liu LL, Xiao YJ, Wang YL, Wang CL, Lin Y, Yu Y, Wang CM, Jiang L, Zhai HQ, Zhao ZG, Wan JM (2016) The catalytic subunit of magnesium-protoporphyrin IX monomethyl ester cyclase forms a chloroplast complex to regulate chlorophyll biosynthesis in rice. Plant Mol Biol 92(1-2): 177-191. https://doi.org/10.1007/s11103-016-0513-4

Lee S, Kim JH, Yoo ES, Lee CH, Hirochika H, An G (2005) Differential regulation of chlorophyll a oxygenase genes in rice. Plant Mol Biol 57(6):805-818. https:// doi.org/10.1007/s11103-005-2066-9

Li CM, Hu Y, Huang R, Ma XZ, Wang Y, Liao TT, Zhong P, Xiao FL, Sun CH, Xu ZJ, Deng XJ, Wang PR (2015) Mutation of FdC2 gene encoding a ferredoxin-like protein with C-terminal extension causes yellow-green leaf phenotype in rice. Plant Sci 238:127-134. https://doi.org/10.1016/j.plantsci.2015.06.010

Li CM, Liu X, Pan JH, Guo J, Wang Q, Chen CP, Li N, Zhang K, Yang B, Sun CH, Deng XJ, Wang PR (2019) A lil3 chlp double mutant with exclusive accumulation of geranylgeranyl chlorophyll displays a lethal phenotype in rice. BMC Plant Biol 19(1):456-470. https://doi.org/10.1186/s12870-019-2028-Z

Lichtenthaler HK, Wellburn AR (1983) Determinations of total carotenoids and chlorophylls $a$ and $b$ of leaf extracts in different solvents. Biochem Soc Trans 11(5):591-592. https://doi.org/10.1042/bst0110591

Lytovchenko A, Eickmeier I, Pons C, Osorio S, Szecowka M, Lehmberg K, Arrivault S, Tohge T, Pineda B, Anton MT, Hedtke B, Lu YH, Fisahn J, Bock R, Stitt M, Grimm B, Granell A, Fernie AR (2011) Tomato fruit photosynthesis is seemingly unimportant in primary metabolism and ripening but plays a considerable role in seed development. Plant Physiol 157(4):1650-1663. https://doi.org/10.1104/pp.111.186874

Ma XZ, Sun XQ, Li CM, Huang R, Sun CH, Wang Y, Xiao FL, Wang Q, Chen PR, Ma FR, Zhang K, Wang PR, Deng XJ (2017) Map-based cloning and characterization of the novel yellow-green leaf gene ys83 in rice (Oryza sativa). Plant Physiol Biochem 111:1-9. https://doi.org/10.1016/j.plaphy.201 6.11 .007

Mauzerall D, Granick S (1955) The occurrence and determination of $\delta$ aminolevulinic acid and porphobilinogen in urine. J Biol Chem 219:435-446 
McCouch SR, Teytelman L, Xu YB, Lobos KB, Clare K, Walton M, Fu BY, Maghirang R, Li ZK, Xing YZ, Zhang QF, Kono I, Yano M, Fjellstrom R, DeClerck G, Schneider D, Cartinhour S, Ware D, Stein L (2002) Development and mapping of 2240 new SSR markers for rice (Oryza sativa L.). DNA Res 9(6): 257-279. https://doi.org/10.1093/dnares/9.6.257

Mochizuki N, Tanaka R, Grimm B, Masuda T, Moulin M, Smith AG, Tanaka A, Terry MJ (2010) The cell biology of tetrapyrroles: a life and death struggle. Trends Plant Sci 15(9):488-498. https://doi.org/10.1016/j.tplants.2010.05.012

Polking GF, Hannapel DJ, Gladon RJ (1995) Characterization of a CDNA encoding 5-aminolevulinic acid dehydratase in tomato (Lycopersicon esculentum Mill.). Plant Cell Rep 14(6):366-369. https://doi.org/10.1007/BF00238598

PöRs Y, Hansen UTE, Hoffmann P (2001) Compensation of differences in light absorption at the levels of photosynthetic primary processes, $\mathrm{CO}_{2}$ uptake and growth of tobacco plants. J Plant Physiol 158(12):1555-1564. https://doi. org/10.1078/0176-1617-00579

Richter A, Peter E, Pörs Y, Lorenzen S, Grimm B, Czarnecki O (2010) Rapid dark repression of 5 -aminolevulinic acid synthesis in green barley leaves. Plant Cell Physiol 51(5):670-681. https://doi.org/10.1093/pcp/pcq047

Sakuraba Y, Rahman ML, Cho SH, Kim YS, Koh HJ, Yoo SC, Paek NC (2013) The rice faded green leaf locus encodes protochlorophyllide oxidoreductase B and is essential for chlorophyll synthesis under high light conditions. Plant J 74(1):122-133. https://doi.org/10.1111/tpj.12110

Sangwan I, O'Brian MR (1993) Expression of the soybean (Glycine max) glutamate 1-semialdehyde aminotransferase gene in symbiotic root nodules. Plant Physiol 102(3):829-834. https://doi.org/10.1104/pp.102.3.829

Song YX, Pu H, Jiang T, Zhang LX, Ouyang M (2016) Crystal structure of glutamate 1-semialdehyde-2,1-aminomutase from Arabidopsis thaliana. Acta Crystallogr Sect F: Struct Biol Commun 72(6):448-456. https://doi.org/10.11 07/S2053230X16007263

Stetefeld J, Jenny M, Burkhard P (2006) Intersubunit signaling in glutamate-1semialdehyde-aminomutase. Proc Natl Acad Sci U S A 103(37):13688-13693. https://doi.org/10.1073/pnas.0600306103

Su N, Hu ML, Wu DX, Wu FQ, Fei GL, Lan Y, Chen XL, Shu XL, Zhang X, Guo XP, Cheng ZJ, Lei CL, Qi CK, Jiang L, Wang HY, Wan JM (2012) Disruption of a rice pentatricopeptide repeat protein causes a seedling-specific albino phenotype and its utilization to enhance seed purity in hybrid rice production. Plant Physiol 159(1):227-238. https://doi.org/10.1104/pp.112.195081

Sun YJ, Ma J, Sun YY, Xu H, Yang ZY, Liu SJ, Jia XW, Zheng HZ (2012) The effects of different water and nitrogen managements on yield and nitrogen use efficiency in hybrid rice of China. Field Crop Res 127:85-98. https://doi.org/1 0.1016/j.fcr.2011.11.015

Tanaka R, Kobayashi K, Masuda T (2011) Tetrapyrrole metabolism in Arabidopsis thaliana. Arabidopsis Book 9:e0145. https://doi.org/10.1199/tab.0145

Tanaka R, Tanaka A (2007) Tetrapyrrole biosynthesis in higher plants. Annu Rev Plant Biol 58(1):321-346. https://doi.org/10.1146/annurev.arplant.57. 032905.105448

Tang WJ, Wang WQ, Chen DQ, Ji Q, Jing YJ, Wang HY, Lin RC (2012) Transposasederived proteins FHY3/FAR1 interact with PHYTOCHROME-INTERACTING FACTOR1 to regulate chlorophyll biosynthesis by modulating HEMB1 during deyellow in Arabidopsis. Plant Cell 24(5):1984-2000. https://doi.org/10.1105/ tpc.112.097022

Tsang EWT, Hu ZY, Chang Q, McGregor Dl, Keller WA (2003a) Expression of a Brassic napus glutamate 1-semialdehyde aminotransferase in Escherichia coli and characterization of the recombinant protein. Protein Expr Purif 29(2): 193-201. https://doi.org/10.1016/S1046-5928(03)00010-X

Tsang EWT, Yang JY, Chang Q, Nowak G, Kolenovsky A, McGregor DI, Keller WA (2003b) Chlorophyll reduction in the seed of Brassica napus with a glutamate 1-semialdehyde aminotransferase antisense gene. Plant Mol Biol 51(2):191201. https://doi.org/10.1023/a:1021102118801

Wang PR, Gao JX, Wan CM, Zhang FT, Xu ZJ, Huang XQ, Sun XQ, Deng XJ (2010) Divinyl chlorophyll(ide) a can be converted to monovinyl chlorophyll(ide) a by a divinyl reductase in rice. Plant Physiol 153(3):994-1003. https://doi.org/1 $0.1104 / p p .110 .158477$

Wang PY, Li CM, Wang Y, Huang R, Sun CH, Xu ZJ, Zhu JQ, Gao XL, Deng XJ, Wang PR (2014) Identification of a geranylgeranyl reductase gene for chlorophyll synthesis in rice. Springer Plus 3(1):201-210. https://doi.org/10.11 86/2193-1801-3-201

Wu ZM, Zhang X, He B, Diao LP, Sheng SL, Wang JL, Guo XP, Su N, Wang LF, Jiang L, Wang CM, Zhai HQ, Wan JM (2007) A chlorophyll-deficient rice mutant with impaired chlorophyllide esterification in chlorophyll biosynthesis. Plant Physiol 145(1):29-40. https://doi.org/10.1104/pp.107.100321
Zhang Y, Su JB, Duan S, Ao Y, Dai JR, Liu J, Wang P, Li YG, Liu B, Feng DR, Wang JF, Wang HB (2011) A highly efficient rice green tissue protoplast system for transient gene expression and studying light/chloroplast-related processes. Plant Methods 7(1):30-44. https://doi.org/10.1186/1746-4811-7-30

Zhao AG, Fang Y, Chen XM, Zhao S, Dong W, Lin YJ, Gong WM, Liu L (2014) Crystal structure of Arabidopsis glutamyl-tRNA reductase in complex with its stimulator protein. Proc Natl Acad Sci U S A 111(18):6630-6663. https://doi. org/10.1073/pnas.1400166111

\section{Publisher's Note}

Springer Nature remains neutral with regard to jurisdictional claims in published maps and institutional affiliations.

\section{Submit your manuscript to a SpringerOpen ${ }^{\circ}$ journal and benefit from:}

- Convenient online submission

- Rigorous peer review

- Open access: articles freely available online

- High visibility within the field

- Retaining the copyright to your article

Submit your next manuscript at $\boldsymbol{\nabla}$ springeropen.com 